
政

\title{
Gender differences in GH response to GHRH+ ARG in lipodystrophic patients with HIV: a key role for body fat distribution
}

\author{
Giulia Brigante ${ }^{1,2}$, Chiara Diazzi ${ }^{1,2}$, Anna Ansaloni ${ }^{1,2}$, Lucia Zirilli ${ }^{1,2}$, \\ Gabriella Orlando ${ }^{3}$, Giovanni Guaraldi ${ }^{3}$ and Vincenzo Rochira ${ }^{1,2}$ \\ ${ }^{1}$ Chair of Endocrinology and Metabolism, Department of Biomedical, Metabolic and Neural Sciences, University of \\ Modena and Reggio Emilia, Modena, Italy, ${ }^{2}$ Division of Endocrinology, Integrated Department of Medicine, \\ Endocrinology and Metabolism, and Geriatrics, Azienda USL of Modena, University of Modena and Reggio Emilia, \\ NOCSAE of Baggiovara, Via Giardini 1355, 41126 Modena, Italy and ${ }^{3}$ Metabolic Clinic, Infectious and Tropical \\ Disease Unit, Department of Medical and Surgical Sciences of Mother, Child and Adult, University of Modena and \\ Reggio Emilia, Modena, Italy
}

\begin{abstract}
Objective: Gender influence on GH secretion in human immunodeficiency virus (HIV)-infected patients is poorly known. Design and methods: To determine the effect of gender, we compared GH response to GH-releasing hormone plus arginine $(\mathrm{GHRH}+\mathrm{Arg})$, and body composition in 103 men and 97 women with HIV and lipodystrophy. The main outcomes were IGF1, basal GH, GH peak and area under the curve (AUC) after GHRH + Arg, body composition, visceral adipose tissue (VAT), and subcutaneous adipose tissue (SAT).

Results: Men had lower GH peak and AUC than women $(P<0.001)$. Of the study population, $21 \%$ of women and $37 \%$ of men had biochemical GH deficiency (GHD; GH peak $<7.5 \mu \mathrm{g} / \mathrm{l})$. VAT-to-SAT ratio was higher in men than in women with GHD $(P<0.05)$. Unlike women, VAT, SAT, and trunk fat were greater in men with GHD than in men without GHD. IGF1 was significantly lower in women with GHD than in women without GHD, but not in men. At univariate analysis, BMI, trunk fat mass, VAT, and total adipose tissue were associated with GH peak and AUC in both sexes $(P<0.05)$. BMI was the most significant predictive factor of GH peak, and AUC at multiregression analysis. Overall, abdominal fat had a less pronounced effect on $\mathrm{GH}$ in females than in males.

Conclusions: These data demonstrate that $\mathrm{GH}$ response to $\mathrm{GHRH}+\mathrm{Arg}$ is significantly lower in HIV-infected males than females, resulting in a higher percentage of GHD in men. Adipose tissue distribution more than fat mass per se seems to account for $\mathrm{GH}$ gender differences and for the alteration of GH-IGF1 status in these patients.

European Journal of

Endocrinology

(2014) 170, 685-696
\end{abstract}

\section{Introduction}

Human immunodeficiency virus (HIV)-infected patients treated with highly active antiretroviral therapy (HAART) are at risk of developing several endocrine and metabolic complications $(1,2)$. Reduced growth hormone $(\mathrm{GH})$ secretion is observed in about one-third of HIV-infected men $(3,4)$ on HAART and it is associated, at least in part, with HIV-related lipodystrophy (5). Furthermore, GH secretion is often impaired in HIV-infected women (6). In both sexes, GH secretion seems to be negatively associated with BMI, waist circumference, and waist-to-hip ratio $(4,6$, 7). However, visceral fat is not strongly associated with $\mathrm{GH}$ impairment in women (8), and increased visceral adiposity does not fully explain the degree of GH deficiency (GHD) in HIV-infected patients of both sexes $(6,8,9)$.

$\mathrm{GH}$ response to $\mathrm{GH}$-releasing hormone plus arginine $(\mathrm{GHRH}+\mathrm{Arg})$ is impaired in HIV-infected men and women even when compared with gender-matched controls $(6,7,8,9)$. Moreover, reduced $\mathrm{GH}$ secretion
(ㄷ) 2014 European Society of Endocrinology Printed in Great Britain
Published by Bioscientifica Ltd. 
seems to occur more frequently in HIV-infected males than in females (6).

In HIV-uninfected subjects, gender is known to have significant effects on basal (10) and pulsatile (11) $\mathrm{GH}$ secretion. Actually, women show higher basal serum GH than men, probably due to different amounts of circulating estrogens. Indeed, estrogens are known to reduce serum insulin-like growth factor 1 (IGF1) and its negative feedback (12), resulting in a greater GH secretory burst mass in women (13). On the other hand, gender seems not to influence $\mathrm{GH}$ response to a provocative test, especially when using the insulin tolerance test or after adjusting the results for BMI, as in the case of GHRH + Arg testing (14).

On this issue, less is known in HIV-infected subjects. Only one study compared GH secretion in HIV-infected men and women (6), showing that women had significantly higher $\mathrm{GH}$ peak and $\mathrm{GH}$ area under the curve (AUC) in response to GHRH + Arg (6). Anyhow, this study was limited by i) the discrepancy between the number of HIV-infected men $(n, 139)$ and that of HIV-infected women $(n, 25)$ and ii) anthropometric parameters and body composition evaluated only by physical examination.

To our knowledge, any previous research protocol compared HIV-infected men and women, with regard to hormonal, metabolic parameters, direct measurements of body composition by means of dual-energy X-ray absorptiometry (DEXA), and abdominal adipose tissue distribution with single-slice computed tomography (CT).

The aim of this study was to determine the effects of gender on GH secretion in HIV-infected patients with lipodystrophy, exploring the relationship among GHIGF1 status, body composition, and metabolic parameters. From a pathophysiologic point of view, it is important to quantify the influence of body composition on $\mathrm{GH}$ secretion in both sexes to better understand the underlying mechanisms of GHD in the context of HIV infection. Moreover, it could have clinical implications because the awareness of gender differences may be important in order to identify true GH-deficient patients and to target treatment strategies.

\section{Subjects and methods}

\section{Subjects}

We prospectively enrolled, at the University of Modena and Reggio Emilia, a total of 207 Caucasian outpatients, between the age of 18 and 69 years, all with HIV-related lipodystrophy. Among outpatients attending the Clinic of Infectious Diseases over a period from June 2005 to
September 2011, only those fulfilling the inclusion and exclusion criteria listed below were selected.

Inclusion criteria - A documented HIV infection for more than 5 years and an ongoing HAART treatment for at least 6 months were mandatory for the enrollment in the study. All the subjects with a physician-confirmed diagnosis of lipodystrophy according to the HIV Outpatients Study definition (15), with or without metabolic alterations, were considered eligible.

Exclusion criteria - Diabetes mellitus; signs, symptoms, or a medical history of pituitary disease; a previous conventional pituitary surgery or radiotherapy; hypogonadism; pregnancy; documented menopause; previous or current treatment with corticosteroids and/or exogenous estrogens; use of oral hypoglycemic drugs, insulin; and a history of recombinant human $\mathrm{GH}(\mathrm{rhGH})$ treatment within the 3 months preceding the enrollment in the study. In order to avoid classes 2 and 3 obesity, that are potential confounding factors for the study of $\mathrm{GH}$ secretion, we restricted the enrollment of HIV-infected subjects with a BMI $<35 \mathrm{~kg} / \mathrm{m}^{2}$.

At the end of the enrollment, 97 females and 103 males were considered eligible. Most of the 97 women enrolled have been previously described (8).

\section{Methods}

All subjects underwent venous blood sampling at $0800 \mathrm{~h}$ after an overnight fast. All blood samples were stored at $-80^{\circ} \mathrm{C}$ until assayed, in the same laboratory. The population enrolled for the research protocol underwent biochemical and endocrinological evaluations including $\mathrm{GHRH}+$ Arg testing.

Assessment of GH secretion and GH-IGF1 axis $>\mathrm{GH}-$ IGF1 axis was studied under basal condition, assaying serum GH, IGF1, and IGF-binding protein 3 (IGFBP3) and under dynamic testing.

A standardized GHRH+Arg test was carried out (GHRH 1-29; GEREF, Serono; $1 \mu \mathrm{g} / \mathrm{kg}$ i.v. at $0 \mathrm{~min}$; arginine clorhydrate, $0.5 \mathrm{~g} / \mathrm{kg}$ i.v. for $30 \mathrm{~min}$, from 0 to $+30 \mathrm{~min}$, up to a dose of $30 \mathrm{~g}$ ). Blood samples were obtained every $15 \mathrm{~min}$, from -15 to $+60 \mathrm{~min}$, then every $30 \mathrm{~min}$ till $120 \mathrm{~min}$, as previously standardized $(16,17)$. This test is considered safe and without side effects $(16,17)$. GH peak response to GHRH+Arg test was evaluated in all the 200 enrolled subjects, according to several cutoff values available in the literature for both 
HIV-infected and HIV-uninfected subjects $(6,7,16,17,18)$. As previously standardized (8), the threshold of GH peak of $7.5 \mu \mathrm{g} / \mathrm{l}$ was used to separate normal from impaired responses to GHRH+Arg in the context of HIV. This was in accordance also to previous studies on HIV-infected subjects $(6,7,9)$ and it is similar, but more restrictive than that of $8.0 \mu \mathrm{g} / 1$ commonly used for overweight subjects even in non-HIV-infected adults (17). Serum GH peak and the AUC were the two parameters considered for the measurement of the amount of $\mathrm{GH}$ in response to $\mathrm{GHRH}+\mathrm{Arg}$.

Other hormonal and biochemical parameters $\boldsymbol{~ S e r u m ~}$ estradiol $\left(\mathrm{E}_{2}\right)$, testosterone, glucose, insulin, and lipid profile (triglycerides, total cholesterol, LDL, and HDL) were measured in all subjects.

HIV infection related parameters $~$ The HIV infection characteristics (i.e. duration of HIV infection, antiretroviral class, and single drug exposure) were obtained from medical records, while CD4 cell count and quantitative plasma HIV RNA viral load were assayed in all enrolled patients.

Body composition and adipose tissue distribution - Anthropometric variables of all the subjects were recorded at medical examination and body composition was measured by means of DEXA and abdominal CT scan.

Patients' weight and height were measured after a 5-h fast by means of a balance and a stadiometer respectively; waist and hip circumferences were expressed as the average of three different measurements $(\mathrm{cm})$.

A whole-body composition study (lean and fat mass) was performed by DEXA (Hologic, Inc., Waltham, MA, USA) as previously standardized (19), with a precision of $3 \%$ for the measurement of fat mass and $1.5 \%$ for fat-free mass (20).

Adipose tissue distribution was studied by a CT scan, with a single-slice abdominal scan at L4 level as in standard protocols. Abdominal visceral adipose tissue (VAT) and abdominal subcutaneous adipose tissue (SAT) were determined (21), with total abdominal adipose tissue (TAT) being the sum of VAT and SAT.

Laboratory analysis $~$ Serum IGF1 was measured by RIA (INCSTAR Corp., Stillwater, MN, USA), with linear reading up to $0.002 \mathrm{nmol} / \mathrm{l}$, and inter- and intra-assay coefficients of variation (CV) of 12 and 8\% respectively. Serum IGFBP3 was measured by immunochemiluminescence (LIAISON Nichols Advantage, San Juan Capistrano, CA, USA), with inter- and intra-assay $\mathrm{CV}$ of 4.8 and $5 \%$ respectively.
Serum GH was measured using a fluoroimmunometric assay (LIAISON DIASORIN Autodelfia hGH Kit, Stillwater, MN, USA) with a sensitivity of $0.02 \mu \mathrm{g} / \mathrm{l}$, with a linear reading up to $80 \mu \mathrm{g} / \mathrm{l}$, and inter- and intra-assay $\mathrm{CV}$ of 5.5 and $4.9 \%$ respectively. Serum $\mathrm{E}_{2}$ was assayed by RIA (Third-Generation DSL-39100, Diagnostic Systems Laboratories, Inc., Webster, TX, USA) with a sensitivity of $2.2 \mathrm{pmol} / \mathrm{l}(0.6 \mathrm{pg} / \mathrm{ml})$, the $\mathrm{CV}$ were $4.1-9.9 \%$ (interassay) and 3.4-3.9\% (intra-assay). Glucose, insulin, and lipid profile (triglycerides, total cholesterol, LDL, and HDL) were assayed using commercially available kits. The CD4 cell count was performed by flow cytometry (Becton Dickinson Immunocytochemistry Systems, San Jose, CA, USA). Quantitative plasma HIV RNA viral load was performed by ultrasensitive method (Amplicor HIV-1 Monitor Assay; Roche Molecular Systems), with the detection range between 50 and 75000 copies $/ \mathrm{ml}$.

\section{Statistical analysis}

The nonparametric Mann-Whitney $U$ test was used for comparisons because most of the variables were not normally distributed by the Kolmogorov-Smirnov test. All the data are shown as median and minimum to maximum (min-max) in parenthesis.

The number of subjects with normal or impaired GH response to $\mathrm{GHRH}+\mathrm{Arg}$ is expressed as percentages, according to different cutoffs.

We evaluated demographic, anthropometric, metabolic, and hormonal variables in order to identify possible predictive factors for $\mathrm{GH}$ response to $\mathrm{GHRH}+\mathrm{Arg}$. A stepwise, linear, multiple regression analysis was performed using serum GH peak and the AUC as dependent variables in two different analyses and age, BMI, total lean body mass, trunk lean mass, trunk fat mass, insulin, triglycerides, waist circumference, serum testosterone, and $\mathrm{E}_{2}$ as independent variables. A second stepwise, linear, multiple regression analysis was performed by using as independent variables of body composition, those obtained by abdominal CT scan (VAT, SAT, and TAT) instead of that obtained by DEXA, without modifying the dependent variables and all the other independent variables. These stepwise, linear, multiple regression analyses were performed twice: i) in all subjects and ii) in men and women separately.

All multiple regression analyses were based on a single regression analysis for each predictor/independent variable that allowed identifying candidate predictive variables. A univariate analysis was carried out before multivariate analysis. The independent variables with 
significance $P$ values of $<0.05$ were entered into the regression model. Stepwise, linear, multiple regression analysis using a backward elimination method was applied to the data with $P<0.10$ as the criterion for a variable to be considered in the model. The percentage of contribution of a given variable to the variance of both the GH peak and the AUC was determined by using the square of the Pearson's correlation coefficient $\left(r^{2}\right)$.

Statistical analysis was performed using the 'Statistical Package for the Social Sciences' Software for Windows (version 16.0; SPSS, Inc., Chicago, IL, USA). For all comparisons, $P$ values $<0.05$ were considered statistically significant.

\section{Ethics}

Written informed consent for participation in the study was obtained from each subject before testing. The Local Institutional Review Board (Comitato Etico di Modena) approved the study (number 158/07).

\section{Results}

Clinical and demographic characteristics and comparison between females and males are shown in Table 1. Age, BMI, waist circumference, waist-to-hip ratio, VAT, VATto-SAT ratio, total and trunk lean mass, serum glucose, triglycerides, and testosterone were significantly higher in HIV-infected men compared with women (Table 1). Basal serum GH, GH peak, AUC, HDL cholesterol, SAT, total and trunk fat mass, and serum $\mathrm{E}_{2}$ were significantly lower in HIV-infected men compared with women (Table 1).

When different cutoffs for the GH peak after GHRH + Arg were considered, the percentage of HIV-infected patients failing to reach a normal GH peak varied according to the cutoff used.

Considering males and females together, $6,7,10,14$, and $29 \%$ failed to reach a GH peak above the thresholds of $2.5,3.3,4.2,5$, and $7.5 \mu \mathrm{g} / \mathrm{l}$ respectively. Using the less restrictive cutoffs of 8 and $9 \mu \mathrm{g} / \mathrm{l}$, commonly used in clinical practice for healthy subjects, 31 and $36 \%$ of the entire cohort failed to reach a normal GH peak above these thresholds.

Considering females and males separately, men were more GH-deficient than women, independently from the cutoff used (Fig. 1). Precisely, 9, 10, 12, 19, 37, 39, and 43\% of males failed to reach a GH peak above $2.5,3.3,4.2,5$, $7.5,8$, and $9 \mu \mathrm{g} / \mathrm{l}$ respectively. Conversely, only $3,5,8,9$, 21,23 , and $28 \%$ of females failed to reach the same thresholds (Fig. 1).
The cutoff of $7.5 \mu \mathrm{g} / \mathrm{l}$ was used to separate HIVinfected men and women with biochemical GHD from those without GHD, as explained in detail in the 'Methods' section. BMI, fat mass (both total and truncal), and VAT, SAT, and TAT were similar in men with GHD compared with women with GHD (Fig. 2). However, men with GHD had higher values of VAT-to-SAT ratio than their female counterparts $(P<0.05$; Fig. 2$)$. Considering total lean mass, women with GHD had lower values (median, $42493 \mathrm{~g}$ and min-max, 32 062-59152 g) compared with men with GHD (median, $59050 \mathrm{~g}$ and min-max, 48 690-73 485) $(P<0.001)$. The intra-gender comparison showed that body composition was not significantly different between women with and without GHD, while in men with GHD trunk fat mass $(P<0.01)$, and VAT and TAT were significantly higher than in men with normal GH peak $(P<0.05)$ (Fig. 3). Total testosterone serum levels did not differ between men with GHD and men with normal GH peak after GHRH + Arg. Conversely, women with GHD had significantly lower serum $\mathrm{E}_{2}$ levels (median, $50 \mathrm{pg} / \mathrm{ml}$ and $\min -\max , 10-238 \mathrm{pg} / \mathrm{ml}$ ) compared with women without GHD (median, $92 \mathrm{pg} / \mathrm{ml}$ and min-max, $10-398 \mathrm{pg} / \mathrm{ml})(P<0.05)$.

No significant difference was found in IGF1 levels in men with normal GH response compared with those with GHD, even when the more restrictive cutoffs were considered. Conversely, IGF1 was significantly higher in women with a normal GH response (median, $159 \mathrm{ng} / \mathrm{ml}$ and $\min -\max , 55.2-395.0 \mathrm{ng} / \mathrm{ml}$ ) than in those with GHD (median, $97.85 \mathrm{ng} / \mathrm{ml}$ and $\min -\max , 25-205 \mathrm{ng} / \mathrm{ml}$ ) $(P<0.001$; Fig. 3).

Considering all enrolled subjects, GH peak ( $r=0.144$, $P<0.05)$ and AUC $(r=0.150, P<0.05)$ were positively correlated with IGF1, but not with basal GH and IGFBP3; IGF1 was positively correlated with IGFBP3 $(r=0.288$, $P<0.0001)$. At univariate analysis carried out according to gender, BMI, trunk fat mass, waist circumference, weight, VAT, and TAT were significantly associated with GH peak in both sexes (Table 2). Age, testosterone, and SAT resulted associated with GH peak only in HIV-infected men, while total and trunk lean mass resulted associated with GH peak only in HIV-infected women (Table 2).

At univariate analysis carried out according to gender, BMI, trunk fat mass, VAT, and TAT were significantly associated with the AUC in both sexes (Table 3). Age and testosterone resulted associated with the AUC only in HIVinfected men, while total and trunk lean mass waist circumference and weight resulted associated with the AUC only in HIV-infected women (Table 3). When considering CT scan parameters, GH peak $(r=0.215$ in 
Table 1 Baseline demographic, anthropometric, HIV-related parameters, and biochemical and hormonal data of HIV-infected males and females with lipodystrophy. Values are expressed as median (min-max).

\begin{tabular}{|c|}
\hline $\begin{array}{l}\text { Age (years) } \\
\text { BMI (kg/m²) } \\
\text { Waist circumference }(\mathrm{cm}) \\
\text { WHR } \\
\text { SAT }\left(\mathrm{cm}^{2}\right) \\
\text { VAT }\left(\mathrm{cm}^{2}\right) \\
\text { TAT }\left(\mathrm{cm}^{2}\right) \\
\text { VAT-to-SAT ratio } \\
\text { Total fat mass }(\mathrm{g}) \\
\text { Total lean mass }(\mathrm{g}) \\
\text { Trunk fat mass }(\mathrm{g}) \\
\text { Trunk lean mass }(\mathrm{g}) \\
\text { Serum IGF1 }(\mathrm{ng} / \mathrm{ml}) \\
\text { Serum IGFBP3 }(\mathrm{ng} / \mathrm{ml}) \\
\text { GH basal }(\mu \mathrm{g} / \mathrm{l}) \\
\text { GH peak }(\mu \mathrm{g} / \mathrm{l}) \\
\text { AUC } \\
\text { Serum glucose }(\mathrm{mg} / \mathrm{dl}) \\
\text { Serum insulin }(\mu \mathrm{lU} / \mathrm{ml}) \\
\text { Serum cholesterol }(\mathrm{mg} / \mathrm{dl}) \\
\text { HDL-cholesterol }(\mathrm{mg} / \mathrm{dl}) \\
\text { LDL-cholesterol }(\mathrm{mg} / \mathrm{dl}) \\
\text { Serum triglycerides }(\mathrm{mg} / \mathrm{dl}) \\
\text { Serum estradiol }(\mathrm{pg} / \mathrm{ml}) \\
\text { Serum testosterone }(\mathrm{ng} / \mathrm{dl}) \\
\text { CD4 count }\left(\mathrm{cell} / \mathrm{mm}{ }^{3}\right) \\
\text { Suppressed viral load, } n(\%) \\
\text { HAART } \\
\text { PI }(\%) \\
\text { NRTI }(\%) \\
\text { NNRTI }(\%)\end{array}$ \\
\hline
\end{tabular}

\begin{tabular}{l}
\hline Normal range \\
\hline NA \\
$<35$ \\
$<80$ \\
$<0.80$ \\
NA \\
NA \\
NA \\
NA \\
NA \\
NA \\
NA \\
NA \\
$94-267$ \\
$3400-6900$ \\
$0.003-1$ \\
$>9$ \\
NA \\
$70-110$ \\
$<15$ \\
$<200$ \\
$>43$ \\
$<115$ \\
$40-150$ \\
M: $20-40 ; \mathrm{F}: 20-400$ \\
M: $300-900 ; \mathrm{F}: 10-110$ \\
$>400$ \\
$<40$ copies/ml \\
NA \\
NA \\
NA \\
\end{tabular}

\begin{tabular}{c}
\hline Males $(n, 103)$ \\
\hline $46(32-65)$ \\
$25.6(18.6-34.6)$ \\
$93(72-121)$ \\
$1(0.9-1.2)$ \\
$150(9-512)$ \\
$162(42-513)$ \\
$304(51-959)$ \\
$1.4(0.3-4.7)$ \\
$11672(2571-24212)$ \\
$57268(41986-84187)$ \\
$7386(1361-14274)$ \\
$28594(18288-42678)$ \\
$133.9(34.4-358)$ \\
$2931(2-6220)$ \\
$0.119(0.014-1.8)$ \\
$10.2(0.5-65.8)$ \\
$636(41-3640)$ \\
$92(63-216)$ \\
$18.6(4.7-96.2)$ \\
$183.5(74-344)$ \\
$40(23-104)$ \\
$109(23-235)$ \\
$193.5(50-837)$ \\
$33(10-100)$ \\
$455(315-1500)$ \\
$500(11-2459)$ \\
$70(68 \%)$ \\
\end{tabular}

33.7

64.1

24.9

\begin{tabular}{c}
\hline Females $(n, 97)$ \\
\hline $43(18-69)$ \\
$24.2(16.9-30)$ \\
$88(70-122)$ \\
$0.9(0.8-1.1)$ \\
$199.50(33-590)$ \\
$109(34-304)$ \\
$338(82-776)$ \\
$0.5(0.1-2.7)$ \\
$15463(3642-35645)$ \\
$41795(26921-59152)$ \\
$8714(1713-17471)$ \\
$21260(13027-31753)$ \\
$140(25-395)$ \\
$3440(500-7370)$ \\
$0.470(0.05-4.3)$ \\
$18.6(1.6-80)$ \\
$1163(112-6126)$ \\
$90(71-127)$ \\
$15.2(0.7-76.2)$ \\
$191(52-308)$ \\
$48(6-94)$ \\
$116.5(33-224)$ \\
$129(40-790)$ \\
$80(10-398)$ \\
$40(10-195)$ \\
$546(23-2516)$ \\
$68(70 \%)$ \\
91 \\
100 \\
58
\end{tabular}

$P$ value

$<0.001$

$<0.05$

$<0.05$

$<0.001$

$<0.001$

$<0.001$

0.497

$<0.001$

$<0.001$

$<0.001$

$<0.05$

$<0.001$

0.441

0.111

$<0.001$

$<0.001$

$<0.001$

$<0.05$

0.078

0.457

$<0.005$

0.201

$<0.001$

$<0.001$

$<0.001$

NA

NA

NA

NA

NA

NA, not applicable; WHR, waist-to-hip ratio; SAT, subcutaneous adipose tissue; VAT, visceral adipose tissue; TAT, total adipose tissue; IGF1, insulin-like growth factor 1; IGFBP3, IGF-binding protein 3; GH, growth hormone; AUC, area under the curve; M, males; F, females; HAART, highly active antiretroviral therapy; $\mathrm{PI}$, protease inhibitors; NRTI, nucleosidic reverse transcriptase inhibitors; NNRTI, non-NRTI.

males and $r=0.349$ in females) and AUC $(r=0.210$ in males and $r=0.347$ in females) were always inversely related to VAT.

$\mathrm{E}_{2}$, insulin, and triglycerides were not associated with GH peak and AUC, both in HIV-infected women and men (Tables 2 and 3). The result of univariate analysis is provided as secondary outcome in order to clarify the possible impact of each variable on GH secretion according to gender. As most of the variables (especially those of body composition) are surrogates of the same phenomenon (e.g. adiposity) and they entered a multiple comparison, the unadjusted statistical output should not be considered very conservative even though it contains useful information.

At stepwise, linear, multiple regression analysis of the whole group, using the parameters of body fat measured by DEXA as independent variables, BMI was the most significant predictive factor for both GH peak $\left(r^{2}=0.152\right)$ and AUC $\left(r^{2}=0.149\right)$, followed by age. Considering gender, BMI remained the most significant predictive factor for both $\mathrm{GH}$ peak $\left(r^{2}=0.160\right)$ and AUC $\left(r^{2}=0.177\right)$ only in females. Otherwise, trunk fat mass was the most significant predictive factor in men for both $\mathrm{GH}$ peak $\left(r^{2}=0.114\right)$ and AUC $\left(r^{2}=0.077\right)$.

A second stepwise, linear, multiple regression analysis of the whole group, using the parameters of body fat measured by abdominal CT scan (SAT, VAT, and TAT), instead of those of DEXA, as independent variables, indicated that BMI was the most significant predicting factor of both GH peak after GHRH + Arg $\left(r^{2}=0.140\right)$ and AUC $\left(r^{2}=0.141\right)$, followed by age. Considering gender, BMI remained the most significant predictive factor for both $\mathrm{GH}$ peak $\left(r^{2}=0.146\right)$ and AUC $\left(r^{2}=0.168\right)$ only in females, followed by VAT. In men, TAT was the most significant predictive factor for $\mathrm{GH}$ peak $\left(r^{2}=0.070\right)$. No variable entered the model when AUC was used as 


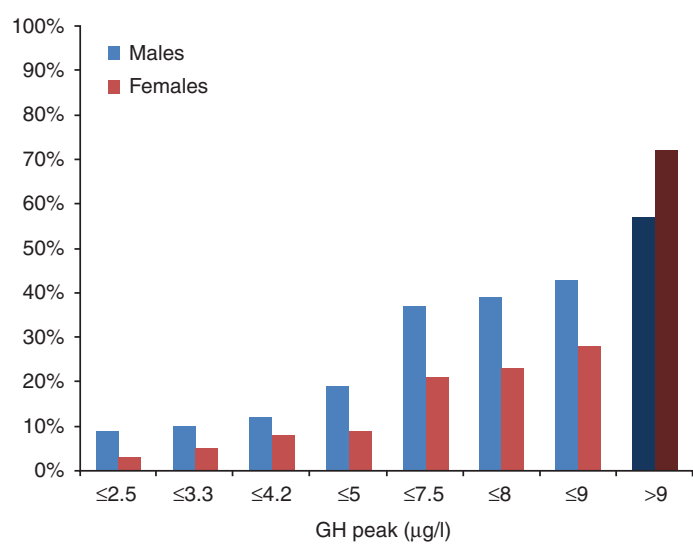

\section{Figure 1}

Comparison of $\mathrm{GH}$ peak response to $\mathrm{GHRH}+$ Arg between HIVinfected males and females according to several cutoffs. Values are expressed as the percentage of subjects whose GH peak was below each different cutoff value or above $9 \mu \mathrm{g} / \mathrm{l}$.

dependent variable in men. No side effects were recorded after GHRH + Arg administration both in men and women with HIV.

\section{Discussion}

The results of the present study, based on a considerable number of HIV-infected lipodystrophic patients, indicate that: i) GH peak and AUC after GHRH+Arg are significantly lower in HIV-infected males than in females; ii) the percentage of $\mathrm{HIV}$-infected subjects failing to respond to GHRH + Arg is higher in men than in women; iii) adipose tissue distribution should play a role in determining such gender differences; and iv) GH response to GHRH + Arg in HIV-infected males and females is more frequently impaired than in the general population.

\section{Gender differences}

The present study confirms that HIV-infected women have higher basal serum GH and they respond to GHRH+Arg better than HIV-infected men, in terms of higher values of $\mathrm{GH}$ peak and AUC. This is in line with previous results obtained in a smaller group of patients (6). This pattern of $\mathrm{GH}$ response to $\mathrm{GHRH}+\mathrm{Arg}$, however, differs from what happens in HIV-uninfected subjects $(14,22)$. Data from the general HIV-uninfected population, in fact, suggest a significant effect of gender on GH regulation (11), but this gender difference seems not to involve $\mathrm{GH}$ secretion elicited by provocative stimuli $(14,22)$. As a matter of fact, gender differences in GH peak and AUC after GHRH+ Arg found in HIV-uninfected subjects were merely ascribed to differences in BMI and are lost after adjusting data for this variable (14). Otherwise, gender differences in basal serum $\mathrm{GH}$ are in accordance with data obtained from HIV-uninfected subjects $(10,11)$.

With this in view, more HIV-infected men could be biochemically classified as GHD than HIV-infected women. The clinical relevance of this finding, as well as its explanation, is difficult to clarify; a few hypotheses, however, can be made. Koutkia et al. suggested that gender difference could be related to the body composition changes typical of the HIV-related lipodystrophy, but, unfortunately, they investigated body composition only through indirect and not easily reproducible tools (BMI, waist circumference, and WHR) (6). When body composition is investigated via two direct methods widely used and validated, such as whole-body DEXA and abdominal CT scan, as in the present study, HIV-infected males show less total body fat mass compared with females, but an unfavorable adipose tissue distribution consisting in higher VAT and VAT-to-SAT ratio than in females. This unfavorable fat distribution is more manifest in HIV-infected men with GHD who have higher trunk fat mass, VAT, and TAT than in HIV-infected men without GHD. Accordingly, VAT is inversely related to GH peak and AUC in HIV-infected men, and trunk fat mass is the most significant predictor of both GH peak and AUC in men at the univariate and multiple regression analyses respectively. This association was less evident in women.

Taken together, all these findings allow to further substantiate the preliminary results obtained by Koutkia et al. (6) and provide evidence that body composition influences $\mathrm{GH}$ peak in HIV-lipodystrophic males more than in females. In particular, $\mathrm{GH}$ response to $\mathrm{GHRH}+\mathrm{Arg}$ is inversely related to visceral fat, especially in men (6). On the other hand, as HIV-infected women had more TAT but a smaller visceral component than men, it seems that the distribution of adipose tissue more than the fat mass per se plays a role in $\mathrm{GH}$ secretion in these patients.

Whether the GHD or the increase in visceral fat comes first remains an unsolved dilemma, as the increase in visceral fat blunts the $\mathrm{GH}$ secretion $(17,23)$, but it is also a consequence of GHD $(24,25)$.

Moreover, it must be said that all the variables associated with $\mathrm{GH}$ response at univariate analysis and those entering the regression models account only for a small part of the GH-IGF1 axis alterations. Indeed, all the factors associated with impaired GH secretion both in 

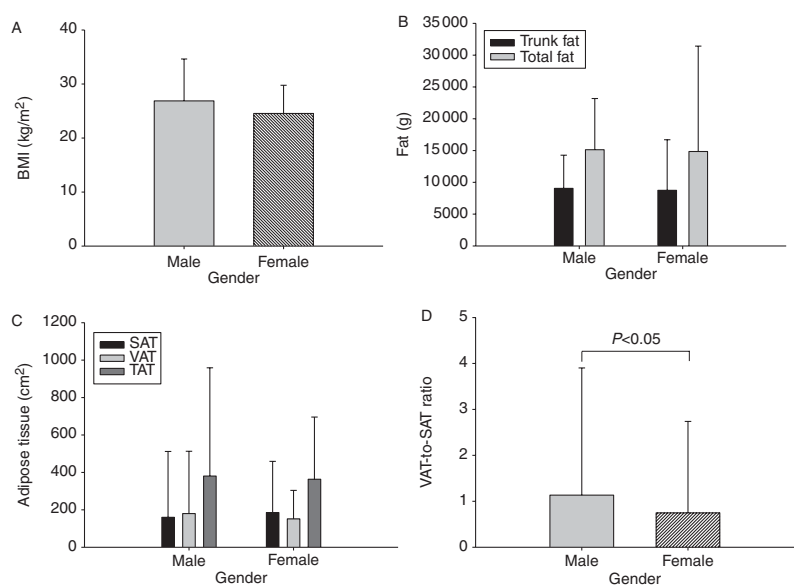

Figure 2

Gender comparison of body composition parameters between males and females with GHD (GH peak $<7.5 \mu \mathrm{g} / \mathrm{l})$. (A) BMI,

(B) total and trunk fat mass measured by DEXA, (C) subcutaneous adipose tissue (SAT), visceral adipose tissue (VAT), and total adipose tissue (TAT) measured by CT scan; (D) VAT-to-SAT ratio. Boxes and bars refer to median and maximum respectively. $P$ values are shown only for significant comparison $(P<0.05)$.

HIV-infected men and women do not fully explain the frequency and severity of GHD in this particular category of patients. For this reason, the role of other factors related to the HIV infection (such as the HIV itself, HAART treatments, the poor general health in these patients, and their chronic inflammation and alterations in immune system) in the genesis of GHD could not be excluded (4, 26). Accordingly, several lines of evidence suggest that in these patients, the HIV status could be considered the strongest predictor of GH response to GHRH+Arg (8), similar to what happens for other pituitary dysfunctions in the context of HIV, such as male hypogonadotropic hypogonadism (27).

\section{Strength and limitations of the study}

The strengths of this study lie: i) in the number of patients of both sexes enrolled, especially women who are often less represented in the HIV cohorts; and ii) in the direct measurement of fat tissue distribution by DEXA and abdominal CT scan. In addition, the methodological approach of this study based on the exclusion of subjects with severe and moderate obesity allows to minimize the detrimental effects of great fat depots on GH secretion.

This study has, however, a few limitations such as the lack of data regarding several factors that might influence GH secretion. The mechanisms involved in the impaired GH secretion in the context of HIV could be related also to: i) increased free fatty acids (FFAs) concentrations; ii) an increased somatostatin tone; and iii) decreased ghrelin $(28,29,30)$. The present study does not provide information on all these three aspects, thus it is not possible to establish to what extent they might contribute to GH gender differences in these patients. From the literature, we know that FFAs impair GH response to secretagogues in both HIV-infected (29) and HIV-uninfected (23) subjects, and that this mechanism operates mainly in men $(3,4,29)$, being probably less pronounced or absent in women $(4,6)$. Furthermore, unlike HIV-uninfected obese subjects, the number of GH pulses is not reduced in HIV-lipodystrophic subjects, but the pulse area and pulse width are markedly decreased (30). This is probably due to an increased somatostatin and FFAs tone and to reduced ghrelin (29). As ghrelin concentrations are about threefold higher in women than in men (31), ghrelin
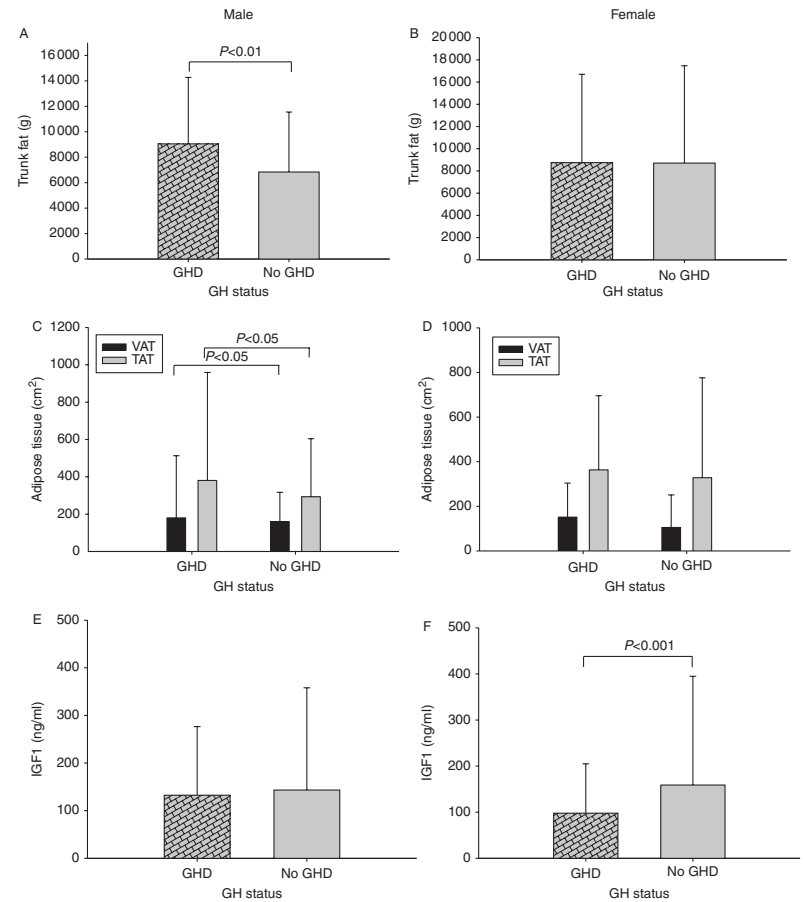

\section{Figure 3}

Male and female intra-gender comparison according to $\mathrm{GH}$ status. The following parameters are drawn: trunk fat mass measured by DEXA (A) in males and (B) in females; visceral adipose tissue (VAT), and total adipose tissue (TAT) measured by CT scan (C) in males and (D) in females; IGF1 (E) in males and (F) in females. Boxes and bars refer to median and maximum respectively. $P$ values are shown only for significant comparison $(P<0.05)$. 
Table 2 Univariate analysis in HIV-infected patients, according to gender. GH peak was considered the dependent variable and all the independent variables were analyzed in men and women separately. Variables significantly associated with the GH peak are in bold.

\begin{tabular}{|c|c|c|c|c|c|c|}
\hline & \multicolumn{6}{|c|}{ Gender } \\
\hline & \multicolumn{3}{|c|}{ Men } & \multicolumn{3}{|c|}{ Women } \\
\hline & $\beta$ & $P$ level & $r^{2}$ & $\beta$ & $P$ level & $r^{2}$ \\
\hline \multicolumn{7}{|l|}{$\begin{array}{l}\text { Dependent variable } \\
\text { GH peak } \\
\text { Independent variables }\end{array}$} \\
\hline $\mathrm{BMI}$ & -0.954 & 0.005 & 0.075 & -1.964 & 0.000 & 0.144 \\
\hline Age & -0.380 & 0.023 & 0.050 & -0.502 & 0.053 & 0.039 \\
\hline Total lean mass & 0.000 & 0.099 & 0.027 & -0.001 & 0.001 & 0.108 \\
\hline Trunk lean mass & 0.000 & 0.155 & 0.020 & -0.002 & 0.001 & 0.113 \\
\hline Trunk fat mass & -0.002 & 0.000 & 0.143 & -0.002 & 0.002 & 0.100 \\
\hline Insulin & 0.011 & 0.872 & 0.000 & -0.186 & 0.137 & 0.023 \\
\hline Triglycerides & -0.140 & 0.067 & 0.034 & -0.011 & 0.483 & 0.005 \\
\hline Waist circumference & -0.309 & 0.017 & 0.056 & -0.541 & 0.001 & 0.107 \\
\hline Weight & -0.223 & 0.018 & 0.054 & -0.555 & 0.002 & 0.099 \\
\hline Estradiol & 0.010 & 0.892 & 0.000 & 0.019 & 0.207 & 0.017 \\
\hline Testosterone & 0.014 & 0.005 & 0.075 & 0.034 & 0.648 & 0.002 \\
\hline VAT & -0.028 & 0.029 & 0.046 & -0.094 & 0.000 & 0.122 \\
\hline SAT & -0.030 & 0.020 & 0.052 & -0.023 & 0.142 & 0.023 \\
\hline TAT & -0.022 & 0.006 & 0.073 & -0.034 & 0.006 & 0.078 \\
\hline
\end{tabular}

GH, growth hormone; VAT, visceral adipose tissue; SAT, subcutaneous adipose tissue; TAT, total adipose tissue.

might also play a role in the sexual dimorphism of GH profiles in HIV-infected patients.

Actually, the evaluation of female subjects tested for GH secretion irrespective of their phase of the menstrual cycle represents another limit of this study. Data from HIV-uninfected subjects suggest a significant effect of gender on GH secretion, the latter being tonic in females and pulsatile, mainly nocturnal, in males (11). Timing of GHRH secretion seems to also be different in the two sexes (10) due to estrogen-related amplification of GHRH secretion, attenuation of somatostatin-negative feedback (13), and inhibition of IGF1 secretion (12). Even though the results of the present study do not allow to exclude that the gender difference found could be due to circulating sex steroids, $\mathrm{E}_{2}$ was not associated with the degree of $\mathrm{GH}$ response to GHRH + Arg at univariate analysis in both HIV-infected men and women and did not enter any stepwise regression models. Testosterone was positively associated with both GH peak and AUC only in HIV-infected men at univariate analysis, but failed to enter the stepwise regression models, thus suggesting a weak association. The lack of information on free IGF1 does not allow drawing any conclusion on IGF1 biological activity and its gender difference in HIV-infected subjects. Another limit of the study is the lack of a control group of HIV-uninfected subjects.
As GHRH + Arg does not check the integrity of the hypothalamic secretion, a possible hypothalamic alteration could not be ruled out. In addition, the lack of information regarding the hypothalamo-pituitary morphology does not allow excluding the coexistence of other causes of GHD in these patients. Morphological alterations of the hypothalamic-pituitary region, indeed, have been described to impair pituitary function in HIVinfected patients, but they are usually associated with other symptoms of hypopituitarism (32).

\section{Clinical relevance of GHD in patients with HIV}

The present study confirms that GHD occurs more frequently in HIV-infected patients than in the general population, as the percentage of patients who fail to respond to GHRH + Arg is higher than that obtained in healthy controls $(16,17,18)$ and of that available from epidemiological data of GHD in adults $(33,34,35)$.

However, whether the impairment of GH secretion in HIV-infected subjects of both sexes represents a clinically relevant GHD or not is still an open issue $(8,26)$. This question is crucial, in clinical practice, in order to establish whether HIV-infected patients require or do not require rhGH replacement treatment. Moreover, the awareness of gender differences may be important in order to identify 
Table 3 Univariate analysis in HIV-infected patients, according to gender. AUC was considered the dependent variable and all the independent variables were analyzed in men and women separately. Variables significantly associated with the AUC are in bold.

\begin{tabular}{|c|c|c|c|c|c|c|}
\hline & \multicolumn{6}{|c|}{ Gender } \\
\hline & \multicolumn{3}{|c|}{ Men } & \multicolumn{3}{|c|}{ Women } \\
\hline & $\beta$ & $P$ level & $r^{2}$ & $\beta$ & $P$ level & $r^{2}$ \\
\hline \multicolumn{7}{|c|}{$\begin{array}{l}\text { Dependent variable } \\
\text { AUC } \\
\text { Independent variables }\end{array}$} \\
\hline $\mathrm{BMI}$ & -54.967 & 0.016 & 0.057 & -151.436 & 0.000 & 0.163 \\
\hline Age & -22.019 & 0.048 & 0.038 & -36.340 & 0.053 & 0.039 \\
\hline Total lean mass & -0.012 & 0.247 & 0.013 & -0.068 & 0.002 & 0.095 \\
\hline Trunk lean mass & -0.016 & 0.368 & 0.008 & -0.126 & 0.002 & 0.102 \\
\hline Trunk fat mass & -0.094 & 0.000 & 0.125 & -0.127 & 0.002 & 0.103 \\
\hline Insulin & 1.837 & 0.700 & 0.002 & -12.656 & 0.162 & 0.021 \\
\hline Triglycerides & -0.907 & 0.071 & 0.033 & -0.653 & 0.571 & 0.003 \\
\hline Waist & -16.307 & 0.057 & 0.035 & -38.958 & 0.001 & 0.106 \\
\hline Weight & -11.531 & 0.067 & 0.033 & -40.264 & 0.002 & 0.099 \\
\hline Estradiol & 0.265 & 0.956 & 0.000 & 1.737 & 0.118 & 0.026 \\
\hline Testosterone & 0.879 & 0.007 & 0.071 & 2.305 & 0.669 & 0.002 \\
\hline VAT & -1.836 & 0.034 & 0.044 & -6.741 & 0.001 & 0.120 \\
\hline SAT & -1.635 & 0.058 & 0.035 & -1.938 & 0.090 & 0.030 \\
\hline TAT & -1.276 & 0.014 & 0.058 & -2.589 & 0.004 & 0.087 \\
\hline
\end{tabular}

GH, growth hormone; VAT, visceral adipose tissue; SAT, subcutaneous adipose tissue; TAT, total adipose tissue.

true GH-deficient subjects and to target treatment strategies.

Certainly, the use of a restrictive cutoff, as $7.5 \mu \mathrm{g} / 1$ (that is lower than that used for overweight patients), results in less misclassification of biochemical GHD. The patient's clinical condition is of little help for the diagnosis because clinical features of the GHD syndrome (such as osteoporosis, muscle mass loss, low energy, muscular weakness, reduced quality of life, and mood disorders) are nonspecific (25), especially in these patients who often present them as part of the HIV infection features.

Similar to previous findings in HIV-infected patients (7), IGFBP3 did not correlate with GH peak and AUC. As far as decreased serum IGF1 is concerned, IGF1 was independent from $\mathrm{GH}$ response to $\mathrm{GHRH}+\mathrm{Arg}$ in men even when more restrictive cutoffs $(2.5,3.3,4.2$, and $5 \mu \mathrm{g} / \mathrm{l})$ were considered, while it was significantly higher in women with normal GH peak compared with women with GHD. IGF1 is not useful for the diagnosis of GHD because it might be normal even in patients with validated GHD due to hypothalamic-pituitary disease $(24,25,36)$. Moreover, even in HIV-uninfected patients with documented GHD due to a hypothalamicpituitary injury, serum IGF1 is often lower in females than in males (37).

On the other hand, the finding of isolated biochemical GHD is not sufficient for the diagnosis of true
GHD because it needs to be coupled with a documented pituitary or hypothalamic disease $(24,36,38)$. In addition, the coexistence of HIV infection excludes the possible diagnosis of idiopathic adult GHD (25). What we talk about regarding GHD in HIV-infected patients still remains a matter of debate and a challenging issue in clinical practice.

For all these reasons, rhGH treatment is not indicated in HIV-infected patients with documented biochemical GHD $(24,36,39)$. Several therapeutic strategies involving the GH-IGF1 system, however, have been undertaken in order to improve health in HIV-infected patients, but with the aim to counteract body composition changes and metabolic alterations due to HIV-related lipodystrophy (40). These strategies include tesamorelin, a GHRH analog $(41,42)$, IGF1 (43), and rhGH $(44,45)$ administration. Unfortunately, all these clinical trials do not consider the GH secretive status of enrolled subjects at baseline and do not target the therapy to the correction of the GHD. Thus, it is not possible to establish, at present, whether these treatments, including physiological rhGH replacement, are more effective in $\mathrm{HIV}$-infected patients with documented severe or mild GHD than in HIV-infected patients with no evidence of GHD. In HIV-uninfected patients, the efficacy of replacement therapy with rhGH strongly depends on the degree of GHD (the more severe the GHD, the more the effective rhGH is) $(46,47)$ and on accurate selection of patients for the treatment $(46,48)$. 
It is possible that a subset of HIV-infected patients with a significant reduction in GH secretory response may benefit from the restoration of normal GH in terms of quality of life, BMD, and VAT.

\section{Conclusions}

The present study provides clinically relevant information improving the knowledge on the frequency of GHD among HIV-infected patients and the influence of gender on the severity of GHD. Accordingly, the diagnosis of GHD is more difficult in men with HIV due to the major interference of fat depots, leading to a higher risk of misclassification in males than females.

In conclusion, impaired GH response to GHRH + Arg is very common in HIV-infected patients with lipodystrophy, and it is more frequent in men than in women. Adipose tissue seems to influence GH peak in males more than in females. However, distribution of adipose tissue more than fat mass per se seems to have a role in the GH-IGF1 status in these patients.

Unfortunately, notwithstanding the improved knowledge on this issue, thanks to these results, the differentiation between biochemical and true GHD in HIV-infected patients is still challenging and further studies are needed to select patients with true GHD and to address them to adequate treatment strategies.

\section{Declaration of interest}

The authors declare that there is no conflict of interest that could be perceived as prejudicing the impartiality of the research reported.

\section{Funding}

This work is based on an independent study protocol, supported by an independent grant from Eli Lilly, Italia (grant number B9R-IT-O051) and sponsored by Ministero dell'Università e della Ricerca (MUR, ex-40\%-2005). Ely Lilly Company did not have any role in the conception/design of the study, in the acquisition, elaboration, and interpretation of data, in drafting/ revising the manuscript, or in the decision to submit the paper for publication.

\section{Author contribution statement}

$\mathrm{L}$ Zirilli and $\mathrm{V}$ Rochira conceptualized and designed the research; G Brigante, C Diazzi, A Ansaloni, L Zirilli, G Orlando, and G Guaraldi carried out the experiments; $G$ Brigante and L Zirilli created the database; G Brigante, C Diazzi, and V Rochira analyzed the data; G Brigante, C Diazzi, and $\mathrm{V}$ Rochira interpreted the results of the experiments; $\mathrm{G}$ Brigante, C Diazzi, A Ansaloni, and V Rochira drafted the manuscript; G Brigante, C Diazzi, G Guaraldi, and V Rochira edited and revised the manuscript; and G Brigante, C Diazzi, A Ansaloni, L Zirilli, G Orlando, G Guaraldi, and $\mathrm{V}$ Rochira approved the final version of the manuscript.

\section{Acknowledgements}

The authors are indebted to Ely Lilly Italia for having co-supported the study, Gilberto Mossetto, Ely Lilly, Italia for his enthusiastic support of this project, and Enrica Baraldi, Maria Cristina De Santis, Laboratory of Endocrinology, AUSL of Modena for technical support in hormonal assays.

\section{References}

1 Brown TT. The effects of HIV-1 infection on endocrine organs. Best Practice \& Research. Clinical Endocrinology \& Metabolism 201125 403-413. (doi:10.1016/j.beem.2011.04.005)

2 Samaras K. Endocrine disease in HIV infection. Best Practice \& Research. Clinical Endocrinology \& Metabolism 201125 vii-viii. (doi:10.1016/ j.beem.2011.04.006)

3 Falutz J. Growth hormone and HIV infection: contribution to disease manifestations and clinical implications. Best Practice \& Research. Clinical Endocrinology \& Metabolism 201125 517-529. (doi:10.1016/ j.beem.2010.11.001)

4 Stanley TL \& Grinspoon SK. GH/GHRH axis in HIV lipodystrophy. Pituitary 200912 143-152. (doi:10.1007/s11102-008-0092-8)

5 Brown TT. Approach to the human immunodeficiency virus-infected patient with lipodystrophy. Journal of Clinical Endocrinology and Metabolism 200893 2937-2945. (doi:10.1210/jc.2008-1019)

6 Koutkia P, Eaton K, You SM, Breu J \& Grinspoon S. Growth hormone secretion among HIV infected patients: effects of gender, race and fat distribution. AIDS 200620 855-862. (doi:10.1097/01.aids.0000218549. 85081.8f)

7 Koutkia P, Canavan B, Breu J \& Grinspoon S. Growth hormone $(\mathrm{GH})$ responses to GH-releasing hormone-arginine testing in human immunodeficiency virus lipodystrophy. Journal of Clinical Endocrinology and Metabolism 200590 32-38. (doi:10.1210/jc.2004-1342)

8 Zirilli L, Orlando G, Carli F, Madeo B, Cocchi S, Diazzi C, Carani C, Guaraldi G \& Rochira V. GH response to GHRH plus arginine is impaired in lipoatrophic women with human immunodeficiency virus compared with controls. European Journal of Endocrinology 2012166 415-424. (doi:10.1530/EJE-11-0829)

9 Lo J, You SM, Wei J, Canavan B \& Grinspoon S. Relationship of peak growth hormone to cardiovascular parameters, waist circumference, lipids and glucose in HIV-infected patients and healthy adults. Clinical Endocrinology 200971 815-822. (doi:10.1111/j.1365-2265. 2009.03603.x)

10 Jessup SK, Dimaraki EV, Symons KV \& Barkan AL. Sexual dimorphism of growth hormone $(\mathrm{GH})$ regulation in humans: endogenous GH-releasing hormone maintains basal GH in women but not in men. Journal of Clinical Endocrinology and Metabolism 200388 4776-4780. (doi:10.1210/jc.2003-030246)

11 Jaffe CA, Ocampo-Lim B, Guo W, Krueger K, Sugahara I, DeMottFriberg R, Bermann M \& Barkan AL. Regulatory mechanisms of growth hormone secretion are sexually dimorphic. Journal of Clinical Investigation 1998102 153-164. (doi:10.1172/JCI2908)

12 Wiedemann E, Schwartz E \& Frantz AG. Acute and chronic estrogen effects upon serum somatomedin activity, growth hormone, and prolactin in man. Journal of Clinical Endocrinology and Metabolism 1976 42 942-952. (doi:10.1210/jcem-42-5-942)

13 Veldhuis JD, Farhy L, Weltman AL, Kuipers J, Weltman J \& Wideman L. Gender modulates sequential suppression and recovery of pulsatile growth hormone secretion by physiological feedback signals in young adults. Journal of Clinical Endocrinology and Metabolism 200590 2874-2881. (doi:10.1210/jc.2004-1363)

14 Qu XD, Gaw Gonzalo IT, Al Sayed MY, Cohan P, Christenson PD, Swerdloff RS, Kelly DF \& Wang C. Influence of body mass index and gender on growth hormone (GH) responses to GH-releasing hormone plus arginine and insulin tolerance tests. Journal of Clinical Endocrinology and Metabolism 200590 1563-1569. (doi:10.1210/jc.2004-1450) 
15 Lichtenstein KA, Ward DJ, Moorman AC, Delaney KM, Young B, Palella FJ Jr, Rhodes PH, Wood KC, Holmberg SD \& HIV Outpatient Study Investigators. Clinical assessment of HIV-associated lipodystrophy in an ambulatory population. AIDS 200115 1389-1398. (doi:10.1097/00002030-200107270-00008)

16 Aimaretti G, Corneli G, Razzore P, Bellone S, Baffoni C, Arvat E, Camanni F \& Ghigo E. Comparison between insulin-induced hypoglycemia and growth hormone (GH)-releasing hormone plus arginine as provocative tests for the diagnosis of GH deficiency in adults. Journal of Clinical Endocrinology and Metabolism $1998 \mathbf{8 3}$ 1615-1618. (doi:10.1210/jcem.83.5.4837)

17 Corneli G, Di Somma C, Baldelli R, Rovere S, Gasco V, Croce CG, Grottoli S, Maccario M, Colao A, Lombardi G et al. The cut-off limits of the GH response to GH-releasing hormone-arginine test related to body mass index. European Journal of Endocrinology 2005153 257-264. (doi:10.1530/eje.1.01967)

18 Aimaretti G, Corneli G, Di Somma C, Baldelli R, Gasco V, Rovere S, Migliaretti G, Colao A, Tamburrano G, Lombardi G et al. Different degrees of GH deficiency evidenced by GHRH + arginine test and IGF1 levels in adults with pituitary disease. Journal of Endocrinological Investigation 200528 247-252.

19 Park YW, Heymsfield SB \& Gallagher D. Are dual-energy X-ray absorptiometry regional estimates associated with visceral adipose tissue mass? International Journal of Obesity and Related Metabolic Disorders 200226 978-983. (doi:10.1038/sj.ijo.0801982)

20 Clasey JL, Bouchard C, Teates CD, Riblett JE, Thorner MO, Hartman ML $\&$ Weltman A. The use of anthropometric and dual-energy X-ray absorptiometry (DXA) measures to estimate total abdominal and abdominal visceral fat in men and women. Obesity Research 19997 256-264. (doi:10.1002/j.1550-8528.1999.tb00404.x)

21 Borkan GA, Gerzof SG, Robbins AH, Hults DE, Silbert CK \& Silbert JE. Assessment of abdominal fat content by computed tomography. American Journal of Clinical Nutrition 198236 172-177.

22 Colao A, Di Somma C, Savastano S, Rota F, Savanelli MC, Aimaretti G \& Lombardi G. A reappraisal of diagnosing GH deficiency in adults: role of gender, age, waist circumference, and body mass index. Journal of Clinical Endocrinology and Metabolism 200994 4414-4422. (doi:10.1210/ jc.2009-1134)

23 Maccario M, Procopio M, Grottoli S, Oleandri SE, Boffano GM, Taliano M, Camanni F \& Ghigo E. Effects of acipimox, an antilipolytic drug, on the growth hormone (GH) response to GH-releasing hormone alone or combined with arginine in obesity. Metabolism $1996 \mathbf{4 5}$ 342-344. (doi:10.1016/S0026-0495(96)90288-7)

24 Ho KK \& GH Deficiency Consensus Workshop Participants. Consensus guidelines for the diagnosis and treatment of adults with GH deficiency II: a statement of the GH Research Society in association with the European Society for Pediatric Endocrinology, Lawson Wilkins Society, European Society of Endocrinology, Japan Endocrine Society, and Endocrine Society of Australia. European Journal of Endocrinology 2007 157 695-700. (doi:10.1530/EJE-07-0631)

25 Melmed S. Idiopathic adult growth hormone deficiency. Journal of Clinical Endocrinology and Metabolism 201398 2187-2197. (doi:10.1210/ jc.2012-4012)

26 Zirilli L, Orlando G, Diazzi C, Squillace N, Carani C, Guaraldi G \& Rochira V. Hypopituitarism and HIV-infection: a new comorbidity in the HAART era? Journal of Endocrinological Investigation 200831 33-38.

27 Rochira V, Zirilli L, Orlando G, Santi D, Brigante G, Diazzi C, Carli F, Carani C \& Guaraldi G. Premature decline of serum total testosterone in HIV-infected men in the HAART-era. PLoS ONE 20116 e28512. (doi:10.1371/journal.pone.0028512)

28 Jain S, Desai N \& Bhangoo A. Pathophysiology of GHRH-growth hormone-IGF1 axis in HIV/AIDS. Reviews in Endocrine \& Metabolic Disorders 201314 113-118. (doi:10.1007/s11154-013-9245-9)

29 Koutkia P, Meininger G, Canavan B, Breu J \& Grinspoon S. Metabolic regulation of growth hormone by free fatty acids, somatostatin, and ghrelin in HIV-lipodystrophy. American Journal of Physiology.
Endocrinology and Metabolism 2004286 E296-E303. (doi:10.1152/ ajpendo.00335.2003)

30 Rietschel P, Hadigan C, Corcoran C, Stanley T, Neubauer G, Gertner J \& Grinspoon S. Assessment of growth hormone dynamics in human immunodeficiency virus-related lipodystrophy. Journal of Clinical Endocrinology and Metabolism 200186 504-510. (doi:10.1210/jcem.86. 2.7175)

31 Barkan AL, Dimaraki EV, Jessup SK, Symons KV, Ermolenko M \& Jaffe CA. Ghrelin secretion in humans is sexually dimorphic, suppressed by somatostatin, and not affected by the ambient growth hormone levels. Journal of Clinical Endocrinology and Metabolism $2003 \mathbf{8 8}$ 2180-2184. (doi:10.1210/jc.2002-021169)

32 Harbeck B, Klose S, Buchfelder M, Brabant G \& Lehnert H. Hypopituitarism in a HIV affected patient. Experimental and Clinical Endocrinology \& Diabetes 2011119 633-635. (doi:10.1055/s-0031-1284366)

33 Erfurth EM. Epidemiology of adult growth hormone deficiency. Prevalence, incidence, mortality and morbidity. Frontiers of Hormone Research 200533 21-32. (doi:10.1159/000088397)

34 Goth MI, Hubina E \& Korbonits M. Aetiology and demography of adult growth hormone deficiency. In Growth Hormone Deficiency in Adults: 10 Years of KIMS, pp 75-82. Eds R Abs \& U Feldt-Rasmussen, Oxford, UK: Oxford PharmaGenesis, 2004.

35 Stochholm K, Gravholt CH, Laursen T, Jørgensen JO, Laurberg P, Andersen M, Kristensen LØ, Feldt-Rasmussen U, Christiansen JS, Frydenberg M et al. Incidence of GH deficiency - a nationwide study. European Journal of Endocrinology 2006155 61-71. (doi:10.1530/eje.1. 02191)

36 Molitch ME, Clemmons DR, Malozowski S, Merriam GR, Vance ML \& Endocrine Society. Evaluation and treatment of adult growth hormone deficiency: an Endocrine Society clinical practice guideline. Journal of Clinical Endocrinology and Metabolism 201196 1587-1609. (doi:10.1210/ jc.2011-0179)

37 Fisker S, Jorgensen JO, Vahl N, Orskov H \& Christiansen JS. Impact of gender and androgen status on IGF1 levels in normal and GH-deficient adults. European Journal of Endocrinology 1999141 601-608. (doi:10.1530/eje.0.1410601)

38 Prodam F, Pagano L, Corneli G, Golisano G, Belcastro S, Busti A, Gasco V, Beccuti G, Grottoli S, Di Somma C et al. Update on epidemiology, etiology, and diagnosis of adult growth hormone deficiency. Journal of Endocrinological Investigation 200831 6-11.

39 Melmed S. Supplemental growth hormone in healthy adults: the endocrinologist's responsibility. Nature Clinical Practice. Endocrinology \& Metabolism 20062 119. (doi:10.1038/ncpendmet0138)

40 Sivakumar T, Mechanic O, Fehmie D \& Paul B. Growth hormone axis treatments for HIV-associated lipodystrophy: a systematic review of placebo-controlled trials. HIV Medicine 201112 453-462. (doi:10.1111/ j.1468-1293.2010.00906.x)

41 Falutz J, Allas S, Blot K, Potvin D, Kotler D, Somero M, Berger D, Brown S, Richmond G, Fessel J et al. Metabolic effects of a growth hormone-releasing factor in patients with HIV. New England Journal of Medicine 2007357 2359-2370. (doi:10.1056/NEJMoa072375)

42 Falutz J, Mamputu JC, Potvin D, Moyle G, Soulban G, Loughrey H, Marsolais C, Turner R \& Grinspoon S. Effects of tesamorelin (TH9507), a growth hormone-releasing factor analog, in human immunodeficiency virus-infected patients with excess abdominal fat: a pooled analysis of two multicenter, double-blind placebocontrolled phase 3 trials with safety extension data. Journal of Clinical Endocrinology and Metabolism 201095 4291-4304. (doi:10.1210/jc. 2010-0490)

43 Kim RJ, Vaghani S, Zifchak LM, Quinn JH, He W, Tebas P \& Frank I. In vitro and in vivo effects of IGF1 on adiposity in HIV-associated metabolic disease: a pilot study. Archives of Medical Research 2013.

44 Glesby MJ, Albu J, Chiu YL, Ham K, Engelson E, He Q, Muthukrishnan V, Ginsberg HN, Donovan D, Ernst J et al. Recombinant human growth hormone and rosiglitazone for abdominal fat accumulation in HIV-infected patients with insulin resistance: a randomized, 
double-blind, placebo-controlled, factorial trial. PLoS ONE 20138 e61. (doi:10.1371/journal.pone.0061160)

45 Lo J, You SM, Liebau J, Lee H \& Grinspoon S. Effects of low-dose growth hormone withdrawal in patients with HIV. Journal of the American Medical Association 2010304 272-274. (doi:10.1001/jama.2010.989)

46 Gasco V, Prodam F, Grottoli S, Marzullo P, Longobardi S, Ghigo E \& Aimaretti G. GH therapy in adult GH deficiency: a review of treatment schedules and the evidence for low starting doses. European Journal of Endocrinology 2013168 R55-R66. (doi:10.1530/EJE-12-0563)
47 Murray RD, Wieringa GE, Lissett CA, Darzy KH, Smethurst LE \& Shalet SM. Low-dose GH replacement improves the adverse lipid profile associated with the adult GH deficiency syndrome. Clinical Endocrinology 200256 525-532. (doi:10.1046/j.1365-2265.2002. 01508.x)

48 Murray RD, Skillicorn CJ, Howell SJ, Lissett CA, Rahim A \& Shalet SM. Dose titration and patient selection increases the efficacy of GH replacement in severely GH deficient adults. Clinical Endocrinology 1999 50 749-757. (doi:10.1046/j.1365-2265.1999.00722.x)

Received 26 November 2013

Revised version received 31 January 2014

Accepted 17 February 2014 